\title{
On the Evolution of Chinese Poetic Painting in Successive Dynasties
}

\author{
Wu Hao \\ College of Humanities, Bohai University, Jinzhou, 121013, China \\ Lindawu_@163.com
}

Key words: poetic painting; ancient; successive dynasties; evolution

\begin{abstract}
As an artistic form that combined the poetry with painting, poetic painting originated in the Han Dynasty. Before the Tang Dynasty the poetry was mainly written on the Book of Odes and the Luoshen Appraisal. The Tang Dynasty, closer integration of poetry and painting, was an important period of giving birth to poetic painting. In the Song Dynasty poetic painting developed into great maturity. On one hand, the concept of blending poetry with painting was established that could be transformed into each other; on the other hand, the application of poetry into painting became a conscious behaviour of artists. The painter, Zhao Mengtiao, Ni Zan and others in the Yuan Dynasty truly led realistic painting into freehand brushwork, expressing the ideal of literati in their mind. The Ming and Qing Dynasties were the flourishing period of poetic painting. The poetic painting of the Ming Dynasty was more flexible and conscious but formal in selecting poems. Poetic painting in the Qing Dynasty basically followed the style of the Ming Dynasty, and paid more attention to the importance and inheritance of the art experience of former generation.
\end{abstract}

\section{Introduction}

Poetic painting was an artistic form that combined the poetry with painting. Pound once remarked that there was a common connection and some artistic qualities between different artistic styles. It was based on the common connection and qualities that the chorus between poetry and painting left the countless moving stories. A poet admired a painting, and then composed a poem to appreciate it. Also, a painter who loved poetry would draw a picture to show its image. These two kinds of artistic behaviours in the history of Chinese art respectively caused the two sorts of unique artistic types: the inscribed poems on painting and poetic painting. Simply, the inscribed poems on painting regarded the painting as the subject and object of poetry while poetic painting regarded poetry as the topic for painting. The inscribed poems on painting and poetic painting demonstrated that Chinese poetry and painting made great efforts to fuse together. This paper focused on poetic painting, and mainly discussed the evolution of Chinese ancient poetic painting in the successive dynasties.

\section{The Beginning Period of Poetic Painting}

On record, Liu Bao, the Han Dynasty painter, was the first one to use a poem in a painting ting in Zhang Yanyuan's Famous Historical Painting Notes, His painting, the Painting Milky Way and the Painting of North Wind that could be described as the origin of poetic painting were created based on the two poems the Milky Way and the North Wind in the Book of Odes, which set an important precedent for posterity.

In the Jin Dynasty more and more painters used poems in their paintings. It was recorded that Emperor Ming in the Jin Dynasty had drawn the Bin Feng, July in the Book of Odes and the Luoshen Appraisal in the fifth volume of Famous Historical Painting Notes. In the entries of Wei Xie in the Jin Dynasty were also documented that Gu Kaizhi had commented the Painting of the North Wind drawn by Wei Xie, so it was thought that Wei Xie had ever drawn the poetic painting of the North Wind. Gu Kaizhi himself loved painting Ji Kang's poetry, and Famous Historical Painting Notes recorded: "Attach great attention to Ji Kang's Chinese classical poem with lines of four characters each, and considered a painting as a poetry. 'It's easy to pluck the five strings with hands, but it's not easy to follow the home-bound swan geese with eyes nostalgically'. he often said. 
" [1] Gu Kaizhi's masterpiece, the Painting on Goddess of the Luo River, was also based on Cao Zhi 's the Luoshen Appraisal. Gu handed down the love story between people and Goddess with vivid image, which had a far-reaching impact on the later poetry. From the ancient records, using poetry in painting by the Jin Dynasty painters mainly focused on the Book of Odes and the Luoshen Appraisal. But poetic painting in the Book of Odes inevitably admonished something and had strong political views.

Till the Tang Dynasty the phenomenon concerning poetic painting was getting more frequent, most of which depicted the poetic in the pure aesthetic level. Wang Wei, the double identity, was both a poet and artist, which made the perfect combination of poetry with painting in the art works. As Fang Yue of the Song Dynasty in the Accidental Talk in the Deep Snow had highly praised Wang Wei's poetic painting: "'the morning rain of Wei Town has laid the light dust clean, and willow trees around the inn look fresh and green. A cup of farewell drinks, oh you, I do entreat, for West across Yang Pass, and friends but seldom meet.' This was Mo Jie's the poem See Yuan-Er Off to Be Prefect in Ansi. It was widely believed that Across Yang Pass was also created by Mo Jie, so both of these two works were called two wit and wisdom men." [2] Similarly, Wang Wei's Wang Chuan collection and the Painting of Wang Chuan collection were defined as Er Miao, two great masterpieces of the times. Both Wang Wei and Pei Di used the technique, a topic derived from a piece of scenery, to produce poetic paintings, and respectively drew two different paintings, but both of them were called the Wang Chuan collection in terms of the twenty landscapes in Wang Chuan. However, Wang Chuan painting was painted by Wang Wei, which was related to the twenty landscapes in Wang Chuan, and these twenty landscapes were in response to the twenty poems. But honestly speaking, Wang Wei did not consider poetry the topic of a painting but combined poetry with painting. That is, he mingled poetry with painting to express a common subject.

In addition to Wang Wei, there were lots of records about the chorus of poetry and painting in other poets and painters of the Tang Dynasty. In The Complete Poetry of the Tang with Zheng Gu's poems of thanks, he specially composed poems for people of the times who should be appreciated according to the Accidental Creation in the Snow. Besides, the poet of the Tang Dynasty, Li Yi's poem was also painted, as Pictorial Knowledge and Old Tang, a biography of Li Yi were recorded:

$\mathrm{Li} \mathrm{Yi,} \mathrm{the} \mathrm{grandfather's} \mathrm{brother's} \mathrm{son's} \mathrm{grandson} \mathrm{in} \mathrm{the} \mathrm{kin} \mathrm{of} \mathrm{prime} \mathrm{minister} \mathrm{in} \mathrm{the} \mathrm{Su} \mathrm{Zong}$ Dynasty, was a successful candidate in the highest imperial examination. He was full of wit and wisdom, and proficient in poetry. His works were the Youth of the Expedition and Set out in the Morning. Someone drew them as a natural barrier, such as "the sand was as white as snow before Hui Yue Mountain, and the moon outside the surrender city was like frost in autumn." [3]

The records showed that Li Yi's poetry was quite popular at that time. Not only was the institution to train musicians and singers eager to take his poetry as lyrics, but also artist loved it. They painted his poetry in a picture, like "the sand was as white as snow before Hui Yue Mountain, and the moon outside the surrender city was like frost in autumn. "

The Tang Dynasty was not only the peak period of poetry, but also the crucial stage of full integration of poetic painting. Above all, it was a great period of the inscribed poems on painting and poetic painting: on one hand, a poem was inscribed on a painting on the basis of painting. Although this phenomenon had existed in the Six Dynasties, the peak age of the inscribed poems on painting exactly derived from $\mathrm{Du}$ Fu; on the other hand, in the aspect of the application of poetry into painting, the Tang poetry provided a perfect topic for a painting as a leader in the poem, so the later poetic painting generally chose to inscribe the Tang poetry on a painting in the successive dynasties.

\section{The Mature Period of Poetic Painting}

Poetic painting experienced the nourishment of the Tang Dynasty from origin to decline and gradually developed into the maturation until the Song Dynasty. The mature period, first and foremost, marked a new kind of concept was finally established that poetry and painting could be transformed into each other on the level of thought. In fact, this establishment of idea should be attributed to Su Shi's literary circle. The most representative one was Su Shi's comment on Wang 
Wei's paintings with the famous remark "picture in the poem" and "poetry in painting". Moreover, using poetry into picturesque became a conscious act. Lin Quan Gao Zhi(A Summery on the Creation of Picturesque) recorded the painter Guo Xi in the Northern Song Dynasty sought massive brilliant sentences in the Jin and Tang poetry during his leisure time in order to inspire empathy, "exquisite feeling and beauty interest", while painting. He and his son even specially compiled picturesque poetry.

Poetic painting in the Song Dynasty achieved a greater development, and Emperor Hui, Zhao Jigong, was credited with leading the Academy of painting to assess the ability of painters through the subject of painting, and then would hire the painters who were specialized in poetic painting as the artists of court painting. For example, the well-known questions about poetic at the time of the examination included "The old temple was deep hidden in the big mountain", "Back from spring with aromatic hooves", "A single red flower in the midst of thick foliage", "Moving spring does not need more", etc. The Academy of painting in the Song Dynasty for the admiration to poetic paintings was undoubtedly an official recognition and advocacy, which exceedingly promoted the advancement of poetic painting.

It is worth mentioning that the application of poetry into painting in the Song Dynasty was not merely confined to show the surface of the image rendering poetry imagery, but also more fit in the mood level to painting and poetry, namely, they were in the pursuit of poetry in painting. The most prominent representative one was Ma Yuan and Xia Gui's painting. Although they did not create plenty of poetic paintings, the composition of their landscape painting was no longer a panoramic view of the landscape like the Song Dynasty. Instead, they used the technique of corner composition, a large blank, to stimulate the viewer's imagination. Take The Ko Ki Yao Lun for example, Ma Yuan's paintings were appraised as follow: "Or cut the peak straight up and not see the top, or the vast wall down can not see the foot, towering mountains and approach the mountains or at the bottom of it, while a man sitting alone, this corner of the king." [4] This technique of expression that combined virtual with realism smoothly communicated with poetry, making paintings displayed the exquisite refinement. This type of painting was no direct description of a sentence in poetry, but adds distinctive poetic characteristics into a painting.

Since the Song Dynasty, led by Su Shi, the literary scholars proposed "literati paintings", to split another style apart from the court painting. In this vein, the tradition of literati paintings came into being that always contended to the palace paintings and commercial painting. The representatives ranged from Wang Wei, Zhao Mengfu and Ni Zan of the Yuan Dynasty, Shen Zhou and Wen Zhengming's Wu Men painting school, Dong Qichang's Song Jiang painting school in the Ming Dynasty to the Four Wangs, Four Monks, and Yang Zhou Eight Eccentric men in the Qing Dynasty. Poetic painting existed in both of these two kinds of traditional paintings but barely belonged to any one of them. Hence, the advancement and evolution of poetic painting was closely related to its competition with the two traditional paintings.

From the Song Dynasty until the Qing Dynasty, palace paintings, commercial paintings and literati paintings all contributed to the fusion of poetry and painting, promoting the development of poetic painting. Su Shi, a group of frustrated scholars, reversed the painting style, and aid a painting through using a poem faced with the defects of palace painting style that was "perfect proficiency was excessive yet implicit meaning picturesque poem was insufficiency".

Su Shi's notion "poetry is a sound picture, and painting is silent poetry" had taken shape in the root of literati paintings which emphasized "the mingling of poetry and picture". The views of the literati also affected the court painting, which laid a foundation for Emperor Hui Zhao Jigong's poetry exam in the Academy of painting as well as the trend of the creation of poetic painting for the Academy of painting.

The Yuan Dynasty was the breakthrough period of literary paintings. Su Shi, Huang Tingjian, Li Gonglin and Mi Fu proposed the concept of literati painting, the communication of poetry with painting, but did not explore a new path in the practice of painting. Therefore, it was Zhao Mengtiao and Ni Zan in the Yuan Dynasty that led the realism of painting to freehand brushwork which expressed the idea of literati scholars. Zhao Mengtiao's The Autumn in Que and Hua Mountains and 
Ni Zan's The Autumn in the Yu Zhuang no longer adhered to the realism of the nature, but expressed the inner ideals or mood by the scenery. Their performance in the landscape painting focused on the painters' personality and ideal themselves, so they established the impressionistic style of literati painting. Zhao Mengtiao and Ni Zan, I figure, had not many poetic paintings, and even the number of poetic painting in the whole of the Yuan Dynasty could not be compared with the Ming and Qing Dynasties, but they played an importance role in opening a channel for the poetry in poetry of the Ming and Qing Dynasty entering the painting, because they led the performance of the artist painting to freehand brushwork, and inspire artists to express their ideal, personality, and mood.

\section{The Peak Period of Poetic Painting}

During the Ming and Qing Dynasties, poetic painting developed into prosperous period that appeared countless poetry, especially Wu Men painting school in the mid of the Ming Dynasty. Shen Zhou, Wen Zhiming, Tang Yin and Qiu Ying as representatives of Suzhou painter, brought about poetry prosperity. They inherited the style of landscape painting in the late of the Yuan Dynasty, and began to draw a set of poetic albums and scrolls. Shen Zhou, though there is no direct performance of the previous poetry, but he was also in the pursuit of the mood of poetry, as Flower Falling Poetry Painting said "It seemed that nobody was in the hill, but he was in harmonious with the surroundings like water falling and flower withering which was not the Tang poem but was very reminiscent of Wang Wei's The Dale of singing birds. Wen Zhiming, Tang Yin, Qiu Ying and others had a lot of poetic creations, especially their students, the representative painters in the late of the Wu School, spread much more poetic paintings. Among them, Lu Zhi, Wen Jia (the second son of Wen Zhiming), Xie Shichen, You Qiu, etc spread the most. After the middle of the Ming Dynasty, Su Zhou painting declined. In the late of the Ming Dynasty, Gao Juhan did not advocate that Su Zhou's business paintings were deemed poetic paintings because of "the formal characteristics, in part, due to their functions of congratulation and decoration, which had the tendency to spoil the effect of poetic painting. He pointed out that the form itself, the size and using made the content more suitable to publicly display rather than retire meditation, more suitable to portray rather than evoke poetic flavor." [5]

The mode of painting, based on poetic painting in the School of Su Zhou, extended from Su Zhou to Fu Jian, Zhe Jiang, Song Jiang and other parts of the country in the late of the Ming Dynasty. This kind of painting not only formed a trend of literati painting, but also very popular with the professional artists. Affected by the trend, Dong Qichang, Zhao Zuo, Song Maojin, Bian Wenyu as representatives of the School of Song Jiang created a large amount of poetic paintings. But the School of Song Jiang did not completely follow the communication of poetry with painting that Su Shi advocated, nor was faithful to the images of poems like the School of Su Zhou, especially its leader Dong Qichang. Lots of poetic painting as he created, there appeared no association between the poems and paintings.

Each of the octavo painting albums was inscribed with the poetry of the Tang Dynasty in The Landscape Poetry hidden in New York Metropolitan Museum of Gallery, but it was futile to find out how the image in each page expressed the poetry. Poetry in the picture seemed to be just a formality and decoration. It could be seen as some intention of Dong Qichang's rebellion against the proliferation of "poetry in painting" style, and a condemnation of Su Zhou's painting fading. While this kind of poetry painting advocated by Dong Qichang maintained the consistent of spirit of leading and resistance in literati painting, it was a kind of block and the separation of poetry and painting in the evolution of poetry. But in other painters' poetic paintings of School of Song Jiang, this resistance is much weaker. For example, in Song Maojin, Zhao Zuo and others' poetic paintings of School of Song Jiang, we could see clearly that they expressed their poetic paintings.

Poetic painting of the Ming Dynasty in the selection of poems were much more flexible and conscious comparing with that of the Song Dynasty. On the Academy of South Song Dynasty stood long poems on the painting scrolls while in the late of the Ming Dynasty on large scrolls were more 
casual couplets. But in the late of Ming Dynasty poetic painting typically was in accordance with the standard artists at that time, and was far more formal about the exhibition of poetry images.

Poetic painting of the Qing Dynasty inherited the characteristics of the poetic painting in the Ming Dynasty. These characteristics were consistent with the art of the Qing Dynasty, which could be regarded as one manifestation of the uniqueness of the art in the Qing Dynasty on the poetic painting. Wang Zhaowen summarized the features of the art of the Qing Dynasty, such as summarization, potentiality, infiltration and transcendence in a history of Chinese Art in the Qing Dynasty. Poetic painting is an unusual form of painting in the Qing Dynasty, also reflects these features, especially the first two. The summary referred to the Qing Dynasty is the master era in the history of Chinese art. Whether artistic creation, art collection or the various aspects comprehensive summaries, they were given about the tradition of previous generation. But this sort of attention and inheritance for artistic experience, produced some defects of lack of personality, and fully embodies on the creation of art, which was fully displayed in the poetic painting of the Qing Dynasty. Poetic painting in the Qing Dynasty basically followed the form of poetry creation in the Ming Dynasty. The Six Artists in the Qing Dynasty (Wang Shimin, Wang Jian, Wang Hui, Wang Yuanqi, Wu Li and Yun Shouping) who were called orthodox advocated reverting to old ways, and they sought skills from the Four Artists in the Yuan Dynasty as well as inherited the tradition of literati painting from Dong Qichang. Propelled by them, the focus of appreciation of art works changed from image into ink, and the traditional elements were an important dimension to appreciate and measure the value of works. The Six Artists in the Qing Dynasty loved painting landscape poetry, whose poetic painting and other landscape painting inherited tradition, pursued ink, but a formula in the layout composition. However, the Four Monks in the Qing Dynasty were exceptions. There was a striking contrast between the Four Wang of the Qing Dynasty (Wang Shimin, Wang Jian, and Wang Hui. Wang Yuanqi) and the Four Monks (Shi Tao, Zhu Da, Jiang, Shi XI). That is, one was in the imperial court, the other was in a civilian society; one was kitsch, the other was a rebel. They were the two branches of literati painting in the Qing Dynasty. The Four Wangs focused on copying the previous works, while the Four Monks were committed to innovation. The Four Monks who pursued nature was quite different from the former one.

Potentiality chiefly referred to "along with the traditional art being the mainstream in the Qing Dynasty, the aesthetic trend of secular art and personality became a productive undercurrent in the progressive development of the art." [6] The development of business, handicraft maturity, and public demand for art in the Qing Dynasty accelerated the commercialization of art. Secular art flourished such as folk prints, New Year paintings, sculpture, toys, embroidery, and pottery. Poetic painting was often drawn in all kinds of crafts. This phenomenon had appeared in the late of the Ming Dynasty. For instance, the popular Ten Chun Zhai Notes and Luo Xuan Bian Gu Notes in the late of the Ming Dynasty chose poetry from the change of ancient poetry and drew poetic painting to add letters into elegance. Till the Qing Dynasty, poetic painting was more widely in all kinds of decorative objects, practical utensils, stationery, and became an indispensable elements in the aesthetic of secular art. The secular tendency in the Qing Dynasty was not only reflected in the prosperity of secular Art, also in the tastes of literati painting. Literati painting from the Song Dynasty to the Ming Dynasty had always been different from the painting of Academy, business painting, walking in the forefront. But literati painting in the Qing Dynasty was closely linked with the secular aesthetic, and no longer quite distinct from each other but "elegant with vulgar", which was related to the famous painters in the Qing Dynasty. Many painters had to sell paintings for a living, including Zheng Banqiao, a Yu, Wu Changshuo, Yuan Jiang, Huang Shen, Yuan Yao, so it was natural to meet the secular aesthetic. School of Yang Zhou and Yang Zhou merchants (especially merchants) contributed to the mutual penetration between elegance and vulgarity. Yang Zhou merchants pursued elegance, and they held the exhibition, formed poetry union, funded painter's travel, like Jin Nong, Li Shan, Wang Shishen, Zheng Banqiao, Fang Huayan. Financial dependence created a compromise that literati painters adjust, so works of gentry and civilian was produced.

Looking into the development of Chinese ancient poetic painting: The Period of Wei and Jin in 
the Han Dynasty the creation was accidental, and was confined to the Book of Odes; The conception that used poem in the painting in the Song Dynasty was established and became painters' conscious behaviour; Literati paintings in the Yuan dynasty explored a new way by making a breakthrough in the technique of painting; The number of poetic painting grew gradually in the Ming Dynasty, and selecting poems was more flexible but revealed formal trend; Till the Qing Dynasty, poetic painting became a common way for artists and the skill of painting gradually turned out to be fixed.

\section{Acknowledgement}

This work is supported by social science fund project of Liaoning province (L12CZW006): Research on the thought pattern of the Western art theories on the construction of China art theories. This work is supported by higher education excellent talented fund project of Liaoning province (WJQ2015002): Research on the evolution of China poetic painting in the successive dynasties.

\section{References}

[1] Y. Y, Zhang, "Famous Historical Painting Notes," Renmin Art of China press, pp. 113, 2004.

[2] Yue, Fang, "The Accidental Talk in the Deep Snow," Commercial Publishing Company, pp. 5, 1936.

[3] R.X. Guo, "Pictorial Knowledge," Shanghai Renmin Art press, pp. 136,1963.

[4] Zhao, Li, Di Yao, J. X., Zhang, "A Brief History of China Ancient Painting," Zhonghua Book Company, Shanghai Ancient Book press, pp. 87, 2010.

[5] X. M. Zhang, "A Journey of Poetry: Poetic Painting in China and Japan," SDX Jiont Publishing Company, pp.71, 2012.

[6] Z. W. Wang, "A History of Chinese Art in the Qing Dynasty," Qilu Book Company, Mingtian Publishing Company, pp.12, 2000. 